\title{
Study of Association Between the Polymorphism of MICA Gene (met 129 val) and Ankylosing Spondylitis in a Sample of the Population of Western Algeria
}

Noria Bouras $^{1 *}$, Ahmed Benzaoui ${ }^{2}$, Ibtissem Messal ${ }^{1}$, Nadjet Boushaba ${ }^{1}$, and Abdallah Boudjema ${ }^{1}$

${ }^{1}$ University of Science and Technology of Oran Mohamed Boudiaf, Oran, Algeria

${ }^{2}$ Department of Rheumatology, University Hospital Center, Oran, Algeria

\begin{abstract}
Ankylosing spondylitis (AS) is a chronic inflammatory rheumatism characterized by a predominantly axial (spinal) localization, followed by joint damage and enthesis. The AS may be associated with other conditions such as reactive arthritis, psoriatic arthritis, chronic inflammation of the intestine and pulmonary manifestation. In this case, we speak of Spondylarthroparies (SPA). The etiology of AS is not well known, however, genetic factors as well as environmental factors can play a very important role in the onset of the disease. Although several genes appear to be associated with SA, the concept of genetic ground relies heavily on the association with HLA-B27 specificity. Recently, the MICA gene has aroused the interest of several studies of associations MICA and autoimmune diseases (MAI), in particular, the association MICA and SA. In our work, we are interested in the polymorphism existing at exon 3 and which encodes the $\alpha 2$ domain of the MICA protein. This polymorphism has the position 129 either the methionine (met) allele or the valine (val) allele. MICA proteins with methionine residue at position 129 react strongly with its NKG2D receptors found on the surface of NK and LT, thereby increasing the cytotoxicity threshold. In contrast, MICA proteins that have a valine residue at the same position have a low affinity with NKG2D. This weakens the threshold of cytotoxicity. The aim of our work is to look for the associations between the polymorphism MICA met129val and the SA in a sample of 90 cases suffering from the SA and 78 controls, within the population of western Algeria. We then tested the effect of this polymorphism on HLA-B27 status. Finally, we looked for a possible association between the MICA-129 genotyping and the early onset of SA. The results show that the MICA-129met allele is strongly associated with SA in patients compared to controls since it is found at an allelic frequency of 0.54 vs $0.30(p=11.10-6)$. On the other hand, the MICA-129val allele is strongly found in the controls than in the cases, with a frequency of 0.70 vs $0.46(p=11.10-4)$. However, the polymorphism MICA met 129 val showed no synergistic or independent effect on the distribution of HLA-B27 specificity in either cases or patients. It is interesting in this case to study other interactions between this polymorphism and other genes or alleles already associated with SA. In our work, we could not determine the effect of MICA-129 genotypes on the early onset of the disease, as reported by another similar study carried out in an Algerian population.
\end{abstract}

Keywords: Ankylosing spondylitis; HLA-B27; MICA; NKG2D; Cytotoxicity

\section{Introduction}

Ankylosing spondylitis (AS) or rheumatic pelvispondy is the second chronic inflammatory rheumatism after rheumatoid arthritis. SA mainly affects the vertebral column (cervical spine, dorsal spine and lumbar spine) and peripheral joints. Ankylosing Spondylitis is a systemic inflammatory disease of multifactorial origin, both polygenic and environmental. The main genetic predisposition factor is located in the HLA region. The disease is, in fact, significantly associated with the HLA-B27 antigen in different ethnic groups. Other genes would appear to be associated with SA including MIC genes. Indeed, the MIC genes belonging to the MHC and neighbouring the HLA-B locus code for MICA and MICB proteins, with restricted distribution. Unlike class I molecules, whose expression is ubiquitous, PCM molecules are expressed preferentially on epithelial and fibroblast cell lines [1] on tumor cell lines of epithelial origin as well as on some freshly isolated tumors [2]. Its normal expression is restricted to the gastrointestinal epithelium and to the cortical thymic epithelium [3]. MIC molecules have no known role in antigen presentation but appear to increase the immune response through a trigger complex between its DAP-10 receptors and their NKG2D ligands expressed on NK (Natural Killer) lymphocytes and certain activated populations of T-lymphocytes alpha/ beta (LT which possess a TCR composed of two $\alpha$ and $\beta$ glycoproteins) and LT gamma/delta (LT with a TCR composed of $\gamma$ and $\delta$ glycoproteins. These LTs are less abundant than LTa $\beta$ since they Are found at $5 \%$ of the total LT and more precisely in the intestinal mucosa) $[4,5]$. In the normal state, the expression of MICA is weak on the surface of the epithelial cell and is not sufficient to lead to the activation of NK and T lymphocytes. In case of cellular stress (infection, tumor, heat shock), The increase in expression of MICA delivers a co-stimulation signal allowing activation of NK and LT. Effector T lymphocytes are activated by antigenic recognition (MHC/antigenic peptide/TCR interaction), and co-stimulated by interaction between NKG2D receptor and MICA molecules. This conjunction of events leads to the proliferation of specific T cells, as well as the activation of cytotoxic functions and production of cytokines. The MICA and MICB molecules, described by the Spies et al. [6] share only about $30 \%$ protein homology homologies with classical HLA class I molecules Extracellular [1]. To date, there are no known functional differences between MICA and MICB. A polymorphism of the MICA molecules has recently been described and which concerns a dimorphism at position 129 of the alpha2 domain.

*Corresponding author: Noria Bouras, University of Science and Technology of Oran Mohamed Boudiaf, El Mnaouar, BP 1505, Bir El Djir 31000, Algeria, Tel: +21341617146; E-mail: noriabouras@yahoo.fr

Received March 22, 2017; Accepted May 22, 2017; Published May 25, 2017

Citation: Bouras N, Benzaoui A, Messal I, Boushaba N, Boudjema A (2017) Study of Association Between the Polymorphism of MICA Gene (met 129 val) and Ankylosing Spondylitis in a Sample of the Population of Western Algeria. J Mol Biomark Diagn 8: 345. doi: 10.4172/2155-9929.1000345

Copyright: ( 2017 Bouras N, et al. This is an open-access article distributed under the terms of the Creative Commons Attribution License, which permits unrestricted use, distribution, and reproduction in any medium, provided the original author and source are credited. 
Citation: Bouras N, Benzaoui A, Messal I, Boushaba N, Boudjema A (2017) Study of Association Between the Polymorphism of MICA Gene (met $129 \mathrm{val}$ ) and Ankylosing Spondylitis in a Sample of the Population of Western Algeria. J Mol Biomark Diagn 8: 345. doi: 10.4172/21559929.1000345

Page 2 of 5

Proteins possessing the amino acid methionine (met) at position 129 have a high binding affinity to NKG2D, whereas proteins with an amino acid valine (val) in the same position have a low affinity. This affects the activation threshold of NK cells and T cell modulation [7]. Having taken these data as a basis, we assume that the polymorphism MICA met 129 val could influence the course of SA development. Thus, we were interested in studying the implication of the polymorphism $M I C A$ met $129 \mathrm{val}$ in the occurrence of SA in a sample of the population of western Algeria.

\section{Materials and Methods}

We carried out a case/control study which covered two populations: Control population composed of 78 unrelated individuals, originating from western Algeria and not suffering from any autoimmune disease, and population of Spondyloarthritis patients Ankylosante, composed of 65 women and 25 unrelated men, all from western Algeria and recruited from the Rheumatology Department, CHU Oran, according to the criteria of Amor [8]. In order to carry out our study, we followed three steps: DNA extraction by the Salting Out technique, amplification by nested PCR of exon 3 of the MICA gene, and finally, Digestion with restriction enzyme RsaI We first amplified a fragment of $2 \mathrm{~Kb}$, from the first intron to the fifth. Second, we amplified exon 3 encompassing the $129 \mathrm{val}$ polymorphism, using the amplification product of the first PCR (Figure 1). In order to carry out these two amplifications, we have arranged two pairs of primers: A sequence-specific primer pair that are at the end of the large fragment $(2 \mathrm{~Kb})$, and another sequencespecific primer pair that encloses exon $3(127 \mathrm{bp})$. The sequences and the amplification conditions for the two pairs of primers are grouped in the Table 1. After amplification of exon 3 of the MICA gene, digestion is carried out in order to determine the presence or absence of the polymorphism which is localized at the level of the codon129. In the case where the site is absent, the amplified DNA will keep the same size of $127 \mathrm{bp}$, which means that the enzyme does not generate a cut (Table 2).

\section{Statistical Analysis}

The statistical analysis was carried out by the compliance test $\chi^{2}$

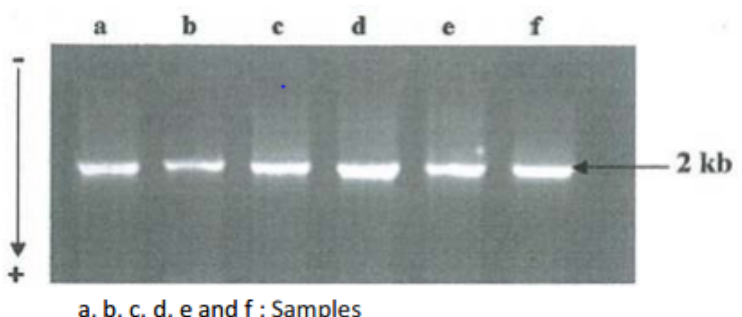

Figure 1: Result of the test of the first amplification of the samples studied by nested PCR.

\begin{tabular}{|c|c|c|c|}
\hline PCR & Primers & DNA sequences 5' to 3' & $\begin{array}{c}\text { Annealing of } \\
\text { primers }\end{array}$ \\
\hline \multirow{2}{*}{$\begin{array}{c}\text { MICA- } \\
\text { specific PCR }\end{array}$} & $\begin{array}{l}\text { Forward } \\
\text { primer }\end{array}$ & 5'-CGTTCTTGTCCCTTTGCCCGTG-3' & \multirow{2}{*}{$68^{\circ}$} \\
\hline & $\begin{array}{l}\text { Reverse } \\
\text { primer }\end{array}$ & 5'-GATGCTGCCCCCATTCCCTTCC-3' & \\
\hline \multirow{2}{*}{$\begin{array}{c}\text { MICA-nested } \\
\text { PCR }\end{array}$} & $\begin{array}{l}\text { Forward } \\
\text { primer }\end{array}$ & 5'-GGGTCTGTGAGATCCATGA-3' & \multirow{2}{*}{$58^{\circ}$} \\
\hline & $\begin{array}{l}\text { Reverse } \\
\text { primer }\end{array}$ & 5'-TGAGCTCTGGAGGACTGGGGTA-3' & \\
\hline
\end{tabular}

Table 1: Conditions of amplification of the large and small fragment.

\begin{tabular}{|l|c|c|c|}
\hline \multirow{3}{*}{ Rsal } & MICA-129 met/met & MICA-129 met/val & MICA-129 val/val \\
\cline { 2 - 4 } & 127 & 127 & \\
\cline { 2 - 4 } & & 104 & 104 \\
\hline
\end{tabular}

Table 2: Correspondence between the fragments of restrictions obtained and the MICA-129 genotypes.

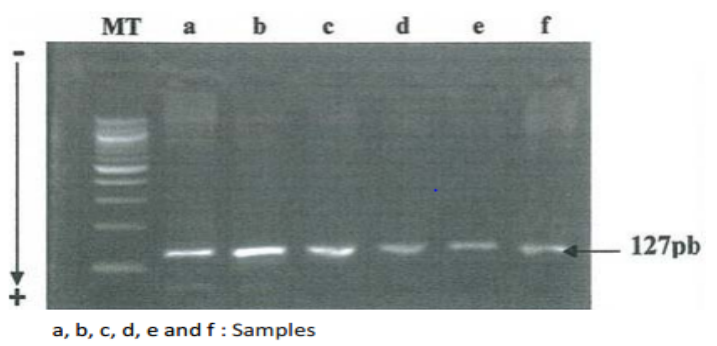

Figure 2: Result of the second amplification test Studied by nested PCR.

which makes it possible to evaluate the significance or not of a difference in distribution, for a given marker, between the patient and control populations. The evaluation of $\chi^{2}$ in this study was carried out using the EpiInfo5.01 software. This software also makes it possible to deduce the degree of significance $\mathrm{p}$, which corresponds to the blindness probability that the overall deviation is attributable only to fluctuations in chance. When the probability p is equal to or less than $0.05(5 \%)$, there is at least 5 chances out of 100 that the distribution results from chance. Thus, the difference in distribution between patient and control populations for a given marker is statistically significant and the marker may be considered associated with the disease. This classical evaluation of $\chi^{2}$ is possible when the numbers are greater than 5 . If not, it is necessary to use a Yates correction (number less than 5), or with the Fisher correction (effective less than 3 ) $[9,10]$. The odds ratio $(\mathrm{OR})$ is also used in cohort and case/control surveys. It allows to appreciate the intensity of an association between a marker and a disease. OR is an estimate of the relative risk in the case where it is impossible to measure the risk of disease in exposed and unexposed subjects $[9,10]$. The OR is always higher than the RR, but in the case of rare diseases and when the RR is not very high, the two measures are very similar (Rumeau-Rouquette et al. 1993). The evaluation of the RR in this study was obtained using the EpiInfo 5.01 software.

\section{Results}

\section{Results of PCR}

For all the DNAs, we obtained the gold of the first PCR a band of the same size $(2 \mathrm{~Kb})$ with a high intensity. It should be noted that we had no non-specific bands at the gel level (Figure 1). This first amplification aims to increase the efficiency of the second PCR to amplify exon 3 which encompasses the studied polymorphism (MICA met 129val). The second PCR allowed us to obtain a small fragment of $127 \mathrm{bp}$ where the MICA polymorphism plays 129val (Figure 2).

Results of the digestion test with the enzyme RsaI: The reading of the electrophoresis and after digestion of the DNAs of the patients showed the 27/90 DNA of the patients carry the MICA-129met/met genotype, 20/90 DNA of the patients carry the genotype MICA-129val/ val and finally $43 / 90$ DNA of the patients present the genotype MICA$129 \mathrm{met} / \mathrm{val}$. Reading of the electrophoresis of the digested control DNAs showed the 7/78 DNA of the controls present the MICA-129met/ met genotype, 38/78 DNA of the controls present the MICA-129val/val genotype, and finally, 33/78 DNA of the controls present the MICA- 
Citation: Bouras N, Benzaoui A, Messal I, Boushaba N, Boudjema A (2017) Study of Association Between the Polymorphism of MICA Gene (met 129 val) and Ankylosing Spondylitis in a Sample of the Population of Western Algeria. J Mol Biomark Diagn 8: 345. doi: 10.4172/21559929.1000345

Page 3 of 5

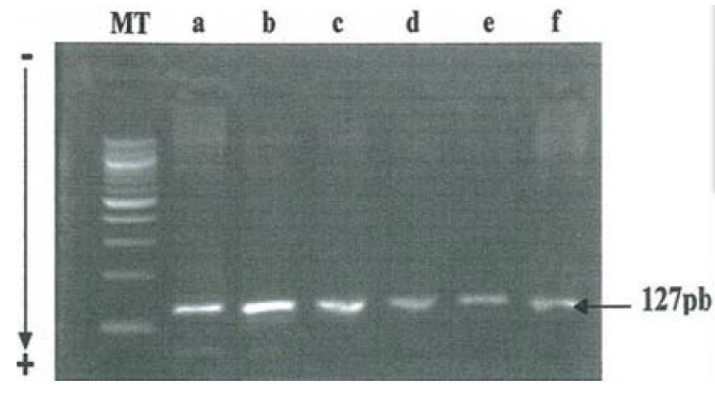

a. b. c. d. e and f : Sambles

Figure 3: Result of the three profiles of the Rsal enzyme digestion test.

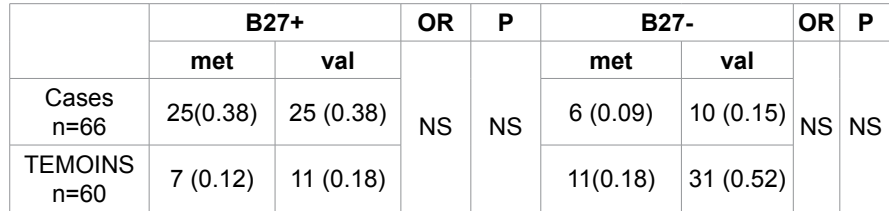

Table 3: Distribution of the MICA allele according to the HLA-B27 status.

\begin{tabular}{|c|c|c|c|c|}
\hline & $\begin{array}{c}\text { MICA- } \\
\text { 129met/129met }\end{array}$ & $\begin{array}{c}\text { MICA-129met/129val or } \\
\text { MICA-129val/129val }\end{array}$ & OR & P \\
\hline $\begin{array}{c}\text { Patients under } \\
40 \text { years } n=36\end{array}$ & 9 & 27 & NS & NS \\
\hline $\begin{array}{c}\text { Patients more } 40 \\
\text { years } n=54\end{array}$ & 18 & 36 & & \\
\hline
\end{tabular}

Table 4: The distribution of the MICA-129 genotype according to two age groups.

\begin{tabular}{|c|c|c|c|c|c|}
\hline Allels & $\begin{array}{l}\text { Cases } \\
n=180\end{array}$ & $\begin{array}{c}\text { Patients } \\
n=156\end{array}$ & OR & $\mathbf{P}$ & IC \\
\hline met & $97(0.54)$ & $47(0.30)$ & \multirow{2}{*}{2.71} & \multirow{2}{*}{0.000011} & \multirow{3}{*}{$\begin{array}{c}\text { IC } \\
(1.69<\mathrm{OR}>4.36\end{array}$} \\
\hline val & $83(0.46)$ & $109(0.70)$ & & & \\
\hline Genotypes & $n=90$ & $n=78$ & & & \\
\hline met/met & $27(0.3)$ & $7(0.09)$ & & \multirow{3}{*}{0.0011} & \\
\hline $\mathrm{val} / \mathrm{val}$ & $20(0.22)$ & $38(0.49)$ & & & \\
\hline met/val & $43(0.48)$ & $33(0.42)$ & & & \\
\hline
\end{tabular}

Table 5: Distribution of polymorphism 129 met / val between cases and controls of western Algeria

$129 \mathrm{met} / \mathrm{val}$ genotype. Figure 3 shows the electrophoretic profile of the 3 genotypes.

\section{Distribution of MICA alleles 129met/val according to HLAB-27}

The analysis of the distribution of the polymorphism of the MICA gene was carried out both in the presence and absence of the HLA-B27. The HLA-B 27 study was carried out of the same population by the team of Messal within the same laboratory [11]. In the presence of HLA-B27, the analysis will demonstrate a synergistic effect between the polymorphism and the HLA-B27 specificity. In the absence of HLA-B27, this stratification could show an independent effect of the studied polymorphism relative to HLA-B27. In both cases, our results showed no statistically significant difference. This polymorphism is not correlated either to the presence of the HLA-B27 specificity or to its absence, since in the presence of the HLAB- 27, the allelic frequencies of the MICA-129met and the MICA-129val found in the cases are identical, i.e. 0.5 for the two frequencies. In the absence of HLAB27, the allelic frequency of $M I C A-129$ met is low compared to that of the MICA-129val allele, in both cases and controls, making the analysis non-significant (Table 3 ).

In our study, this lack of significance may be due to the small number of subjects involved in HLA-B27 stratification. Effect on 90 cases and 78 controls, only 33 cases and 30 controls were affected by this stratification, as these DNAs represent the only DNA whose HLA-B27 status was determined (Table 3 ). It is therefore necessary to stratify all the cases and controls according to HLA-B27.

\section{Distribution of polymorphism according to age in cases}

Ankylosing Spondylitis is a disease that can occur at an early age in children between 4 to 16 years of age. However, the majority of studies show that diagnosis is made before the age of 40, whether in HLAB27 + or B27- patients [12]. To this end, we tried to find an association between the polymorphism studied and the early age of the disease. Thus, we have grouped the patients according to two age groups: the patients under 40 years and those of more than 40 years. We then studied the distribution of the MICA-129 genotype according to these two age groups. The results obtained show no association between the three genotypes found in the cases and the two age groups (Table 4).

\section{Discussion}

The analysis of the results of the MICAmet129val genotyping showed a predominance of the MICA-129met allele in the cases compared to the controls. Its allelic frequency in the cases is 0.54 whereas it is 0.30 in the controls $(\mathrm{p}=11.10-6)$ (Table 5). It would seem that the MICA-129met allele is susceptibility by bringing a risk higher than $1(\mathrm{OR}=2.71)$. Our results are perfectly consistent with those found by Amroun and his team in an Algerian population of 129 cases and 76 controls [13]. This suggests a significant association between the MICA129 met genotype and the disease with genotypic frequencies of 0.81 in the patients and 0.62 in the controls and a risk of 2.57 which is very close to that obtained in our present Study Amroun et al. [13]. Analysis of the distribution of the met/met, met/val and val/val genotypes in the two groups showed a significant increase in the met/met genotype in the cases compared with controls $(0,30$ vs 0,$09 ; \mathrm{p}=0.0011)$ (Table 5). Concerning age stratification, the results obtained. In our study show no association between the three genotypes found in the cases and the two age groups (Table 4). On the other hand, the results obtained by the Amroun team show an important association between the MICA129 met allele in the homozygous state and the early form of the disease, since $60 \%$ of the cases, which carry the met/met genotype, Had their first attack at an early age (15 years), independently of HLA B27. From the results obtained in the study of Amroun and those of our present work, it appears that the presence of the MICA-129met allele is a factor of susceptibility to the occurrence of SA. The expression of this allele could play a very important role in the MICA-NKG2D interaction. Indeed, a person carrying the MICA-129met allele, and undergoing cellular stress, will develop cytotoxicity caused by NK and LT $\gamma / \delta$, and this in gastrointestinal epithelial cells, endothelial cells or fibroblasts Tumor or viral infections $[6,2,14]$. This event would activate macrophages and $70 \%$ to $90 \%$ of $\gamma / \delta$ T lymphocytes with their NKG2D receptor $[12,2]$. Thus, a genetically predisposed subject, and in the presence of a causative agent (stress), will trigger an autoimmune disease such as spondylarthritis or spondyloarthropathies. The activation signal of NK cells, in the presence of the MICA-129met allele and in the presence of stress, dominates the inhibitory signal induced by the recognition of NKG2D by MHC class I proteins [2]. Thus, while MHC class I proteins indicate cell integrity to TCR and NK cell receptors, the MICA protein, for its part, informs cellular stress and thus induces an immune response even when MHC Class I proteins are the association NKG2D -MICA depends on a simple amino acid substitution at position 129 in the alpha2 domain. The variable affinities of the MICA alleles for NKG2D may affect the activation threshold of NK cells and the modulation of 
Citation: Bouras N, Benzaoui A, Messal I, Boushaba N, Boudjema A (2017) Study of Association Between the Polymorphism of MICA Gene (met $129 \mathrm{val}$ ) and Ankylosing Spondylitis in a Sample of the Population of Western Algeria. J Mol Biomark Diagn 8: 345. doi: 10.4172/21559929.1000345

Page 4 of 5

T cells. Thus, MICA molecules which carry a methionine instead of a valine at position 129 have a strong Affinity with NKG2D receptors. They will increase the activation threshold of cytotoxicity-inducing NK. On the other hand, molecules carrying the amino acid valine at position 129 have a low affinity for NKG2D thus decreasing NK activation [7]. From these data, we can understand the effect of MICA-129met polymorphism on SA by triggering cytotoxicity and autoimmunity in genetically predisposed individuals and undergoing cellular stressors. Another study concerning the MICA-129 polymorphism was described by a Tunisian team on nasopharyngeal cancer. On the other hand, it showed a strong association between MICA 129val and the disease [15]. This explains why tumor proliferation may be due to the low affinity between MICA-129val and NKG2D. Consequently, cellular resistance is established, thus avoiding their elimination by NK and LT.

This observation seems to contradict the results observed in the study of the effect of this polymorphism in the occurrence of autoimmune diseases. Indeed, in the MAI, it is the presence of the MICA-129met allele that is susceptible to the occurrence of these diseases by the activation of cytotoxicity induced by NK and LT. On the other hand, in the case of cancers, the absence of NK activation in subjects with the MICA-129val allele leads to the escape of these cancer cells to the destructive action of NK. The study on nasopharyngeal cancer in Tunisia has clearly determined the association MICA-129val and the evolution of this cancer. This association also depends on the HLA-E gene. The HLA-E $E^{\star} 0103 / M I C A-129$ met haplotype is associated with an earlier occurrence of this tumor, whereas the HLA-E* 0101/ MICA- 129met and $\mathrm{E}^{\star}$ 0103/MICA-129met haplotypes are protective by delaying. The occurrence of this cancer [15]. The MICA-129val allele may in this case have an additive role in the onset of the disease and that the MICA-129met allele could play a protective role by increasing Cytotoxicity even in the presence of HLA-E, since the latter is the ligand of the inhibitory receptor CD49/NKG2A expressed on the NK [16]. In this case, the expression of MICA molecules is a means of controlling the growth of tumor cells and escaping the immune system [7]. Another Tunisian study on two cancers, colorectal cancer CRC and gastric cancer GC are determined that the MICA-129 Val allele was significantly more frequent in CRC and GC patients than controls (for CRC patients: $65 \%$ vs $55 \%$ for the controls, $\mathrm{p}=0.006, \mathrm{pc}=0.012, \mathrm{OR}=1.5$, and $95 \% \mathrm{CI}(1.11-$ 2.01); for GC patients: $69 \%$ vs. $55 \%$ for the controls, $\mathrm{p}=0.007, \mathrm{pc}=0.014$, $\mathrm{OR}=1.8$, and $95 \% \mathrm{CI}(1.17-2.78)$. Whereas, MICA-129 Met allele was significantly more frequent in control than in patient groups (for CRC: $35 \%$ vs $45 \%, \mathrm{pc}=0.012, \mathrm{OR}=0.67$, and $95 \%$ CI $(0.49-0.90)$; for GC: $31 \%$ vs. $45 \%, \mathrm{pc}=0.014, \mathrm{OR}=0.56$, and $95 \% \mathrm{CI}(0.35$ to 0.87$))$. The analysis of the distribution of the different genotypes between the three groups revealed that the MICA-129 Val/Val genotype is significantly associated with CRC and patients rather than controls (for CRC: $33 \%$ vs $19 \%$, $\mathrm{p}=0.006 ; \mathrm{pc}=0.018, \mathrm{OR}=2.09$, and $95 \% \mathrm{CI}=(1.28$ to 3.43$)$; for $\mathrm{GC}: 41 \%$ vs $19 \%, \mathrm{pc}=1.5610-3, \mathrm{OR}=2.92$, and $95 \% \mathrm{CI}=(1.49-5.65)$ [17]. Other associations have been described with other MAIs: MICA-A6/Behçet allele in Japanese, MICA-A5.1/Celiac in Spanish, MICA-4/Type I diabetes in Koreans, MICA-A9/Psoriasis, MICA-A5, MICA-A5.1/LED in Italian and $M I C A-A 4 / P R$. It is interesting to note that all these alleles have the amino acid methionine at position 129. Thus, the presence of the MICA-129met allele may be associated with the occurrence of SA and can also protect against the development of certain cancers and this, by triggering cytotoxicity via the MICA-NKG2D complex [18].

\section{Conclusion}

The gene MICA, genes related to HLA class I molecules, has been the subject of several studies of associations with different MAI and this through its various alleles. In our work, we were interested in the implication of this polymorphism MICA met129val in the development of the SA in a sample of the population of the Algerian West. We found a significant association between the MICA-129met allele and SA.

This association is perfectly correlated with the results of the work carried out in an Algerian population. On the other hand, the MICA129 val allele does not appear to be associated with SA or MAI, but it is correlated with the development of cancers. Thus, the presence of the MICA-129met allele may be associated with the onset of SA and may also protect against the development of certain cancers by initiating cytotoxicity via the MICANKG2D complex. It would be interesting to study MICA met129val polymorphism in other autoimmune diseases, including chronic intestinal diseases such as Crohn's disease and celiac disease, for possible association.

Concerning the effect of this polymorphism on the development of SA in relation to the HLAB27 status, which represents the most important genetic factor at the onset of SA, the results obtained showed no synergistic or Polymorphism with respect to HLA-B27 specificity. It remains interesting to study the influence of this polymorphism on other HLA or non-HLA genes, already associated with SA, such as the HLA-DR4 allele of the HLADRB1 gene, the HLA-DQB1 gene, HLA$D P B 1$, IL-1 clusters, the TNF $\alpha$ gene or also the CARD15 gene.

\section{References}

1. Amor B, Dougados M, Mijiyawa M (1990) Diagnostic criteria for spondyloarthropathies. Rev Rhum 57: 85-89.

2. Amroun H, Djoudi h, Busson M, Allat R, El Sherbini M, et al. (2005) Early-onset ankylosing spondylitis is Associated with a functional MICA polymorphism. Hum Immunol 66: 1057-1061.

3. Bahram S (2000) MIC genes from genetics to biology. Adv Immunol 76: 1-60.

4. Bauer S, Groh V, Wu J, Steinle A, Phillips JH, Lanier LL, et al. (1999) Activation of NK cells and T cells by NKG2D, a receptor for stress-inducible MICA. Science 285: 727-729.

5. Clerget-Darpoux F, Babron MC, Prum B, Lathrop GM, Deschamps I, et al (1988) A new method to test genetic models in HLA associated diseases: The MASC method. Ann Hum Genet 52: 247-258.

6. Das H, Groh V, Kuijl C, Sugita M, Morita CT, et al. (2001) MICA engagement by human $\mathrm{V}$ gamma2Vdelta2 T-cells enhances their antigen dependent effector function. Immunity 15: 83-93.

7. Douika H, Arij Ben Chaabena B, Romdhanec A, Ben Romdhaned H, et al (2009) Association of MICA-129 polymorphism with nasopharyngeal cancer risk in a Tunisian population. Hum Immunol 70: 45-48.

8. Groh V, Bahram S, Bauer S, Herman A, Beauchamp M, et al. (1996) Cell stress regulated human major histocompatibility complex class I gene expressed in gastrointestinal epithelium. PNAS USA 93: 12445-12450.

9. Groh V, Rhinehart R, Secrist H, Bauer S, Grabstein KH, et al. (2003) Prevalence of rheumatoid arthritis and spondylarthropathies in France. Ann Rheum Dis 62 190-198.

10. Koning F, Knot M, Wassenaar F, Van den Elsen P (1989) Phenotypical heterogeneity among human $T$ cell receptor gamma/delta-expressing clones derived from peripheral blood. Eur J Immunol 11: 19-23.

11. Messal I (2009) Personal communication. Implication of HLA-B27 specificity in Ankylosing Spondylitis.

12. Moretta A, Bottino C, Vitale M, Pende D, Cantoni C, et al. (2001) Activating receptors and coreceptors involved in human natural killer cellmediated cytolysis. Annu Rev Immunol 19: 197-223.

13. Spies T, Bahram S, Bresnahan M, Geraghty DE (1994) A second lineage of mammalian major histocompatibility complex class I genes. PNAS USA 91 6259-6263.

14. Stephens LA, Mason D (2001) Characterisation of thymus-derived regulatory $T$ cells that protect against organ-specific autoimmune disease. Microbes Infect 11: $905-910$.

15. Steinle A, Li P, Morris DL, Groh V, Lanier LL, et al. (2001) Interactions of human 
Citation: Bouras N, Benzaoui A, Messal I, Boushaba N, Boudjema A (2017) Study of Association Between the Polymorphism of MICA Gene (met 129 val) and Ankylosing Spondylitis in a Sample of the Population of Western Algeria. J Mol Biomark Diagn 8: 345. doi: 10.4172/21559929.1000345

Page 5 of 5

NKG2D with its ligands MICA, MICB, and homologs of the mouse RAE-1 protein family. Immunogenetics 53: 279-287.

16. Svejgaard A, Nielsen LS, Svejgaard E, Nielsen FK, Hjortshoj A, et al. (1974) HLA in psoriasis vulgaris and in pustular psoriasis-population and family studies. Br J Dermatol 9: 145-153.
17. Fayza A, Chaaben Arij B, Olfa B, Nesrine O, Hajer A, et al. (2017) Ryad3 MICA-129 Met/Val variant as possible biomarker of diagnosis and prognostic of gastro-intestinal tract carcinomas. J Mol Biomark Diagn S2-031.

18. Wu J, Song Y, Bakker AB, Bauer S, Spies T, et al. (1999) An activating immunoreceptor complex formed by NKG2D and DAP10. Science 285: 730-732. 